\title{
Assessment of Main Parameters of Extreme Earthquakes in Red Sea, West Coast of Saudi Arabia
}

\author{
Said Ali El-Quliti', Tawfiq Bin Saeed Al-Harbi², Mahdi Bin Salem Al-Yami³, \\ Ahmed Bin Matar Al-Ghamdi ${ }^{4}$, Mohammed Bin Mattar Al-Shammari ${ }^{5}$ \\ ${ }^{1}$ Department of Industrial Engineering, King Abdulaziz University, Jeddah, KSA \\ ${ }^{2}$ Department of Geophysics at the National Center for Earthquakes and Volcanoes, Saudi Geological Survey, \\ Jeddah, Saudi Arabia \\ ${ }^{3}$ The Company Cover Environmental Studies and Environmental Consulting in Saudi Arabia, Jeddah, Saudi Arabia \\ ${ }^{4}$ Fire and Rescue Division of the General Directorate of Civil Defense, Jeddah, Saudi Arabia \\ ${ }^{5}$ Department of Fire and Rescue Services, Civil Aviation Authority Province of Hail in Saudi Arabia, \\ Jeddah, Saudi Arabia \\ Email: tawfiqalharbi2002@hotmail.com
}

Received 30 March 2016; accepted 28 May 2016; published 31 May 2016

Copyright (C) 2016 by authors and Scientific Research Publishing Inc.

This work is licensed under the Creative Commons Attribution International License (CC BY).

http://creativecommons.org/licenses/by/4.0/

(c) (i) Open Access

\section{Abstract}

The negative effects of natural disasters on human life exist from the foot and did not occur at a specific time but found since the creation of mankind. Humans coexist with extreme events all the time, only when the intensity of the event becomes greater than a certain level there is a resulting disaster. Small earthquakes occur all of the time with no adverse effects. Only large earthquakes cause disasters. Statistical analysis reveals that larger events occur less frequently than small events. Through the large number of seismic events, we find that at the end of the year may have a series of seismic events with different values depending on the strength of activity whether it is high or low on Richter scale and the assessment is only for the greatest value in a year even if recurring this value and the volume of dangerous increases and the frequency of their occurrence according to an ongoing activity, major disasters result from a small number of events and sustained results in a large and devastating event, and can be represented by these results and amounts On a log-scale which points are almost on a straight line and a clear indication of the evaluation event. Through previous data analysis we can understand the following events behavior for coordination and guidance on the development of evacuation plans on the expected future and use a Weibull equation to estimate the frequency of the event and the return again as a percentage for each event and the probability of the occurrence of a particular earthquake to some degree on the Richter scale in the sea during any period. Past records of earthquakes at the West Coast of the Kingdom of Saudi Arabia (Red Sea) for years 1913-2016 are used to predict future conditions concerning the annual frequency, the return period, the percentage probability for each event, and the probability of a certain-magnitude 


\title{
earthquake occurring in the region during any period.
}

\section{Keywords}

\author{
Red Sea, Earthquakes, Assessment, Saudi Arabia
}

\section{Introduction}

The natural disaster damaged the old man's life does not specify a period of time, and perhaps the most important "earthquakes" that threatens "human civilization". The most destructive disaster of nature is a severe earthquake and its destroying effects. If the earthquake occurs in a populated area, it may cause many deaths and injuries and extensive property damage regions. The ultimate goal of seismic hazard assessment and risk evaluation for a particular site or area is to condense seism-tectonic knowledge and experience into parameters used for predicting seismic parameters which in turn can be applied by engineers in design and subsequent earthquake resistant construction.

Statistical surveys support researches on the likelihood of future earthquakes. A primary goal of earthquake research is to increase the reliability of earthquake probability estimates. With a greater understanding of the hazard parameters of earthquakes, we may be able to reduce damage and loss of life from this destructive event. Statistics help us to predict the future events based on previous events.

\subsection{Seismicity of the West Coast of Saudi Arabia}

We find that in the western region of Saudi Arabia is growing concern on the volcanic activity associated with earthquakes in the Red Sea have been the work of affluent studies to assess the seismic risk level. Western Region of Saudi Arabia is considered to be a moderately active seismic zone as shown in Figure 1 [1]. Seismic events also include a sequence of earthquakes which occurred in 1967 along the Red Sea rift system at a distance of about $150 \mathrm{~km}$ to the south west of Jeddah [2]. In [3], a report that a high level of micro-earthquake activity was detected near the border of the Red Sea and near the transition from oceanic to continental crust. Recently, EI-Isa et al. [4] reported that about 500 local earthquakes with magnitudes less than 4.85, occurred in the Gulf of Aqaba area during the period from January 21 to April 20, 1983.

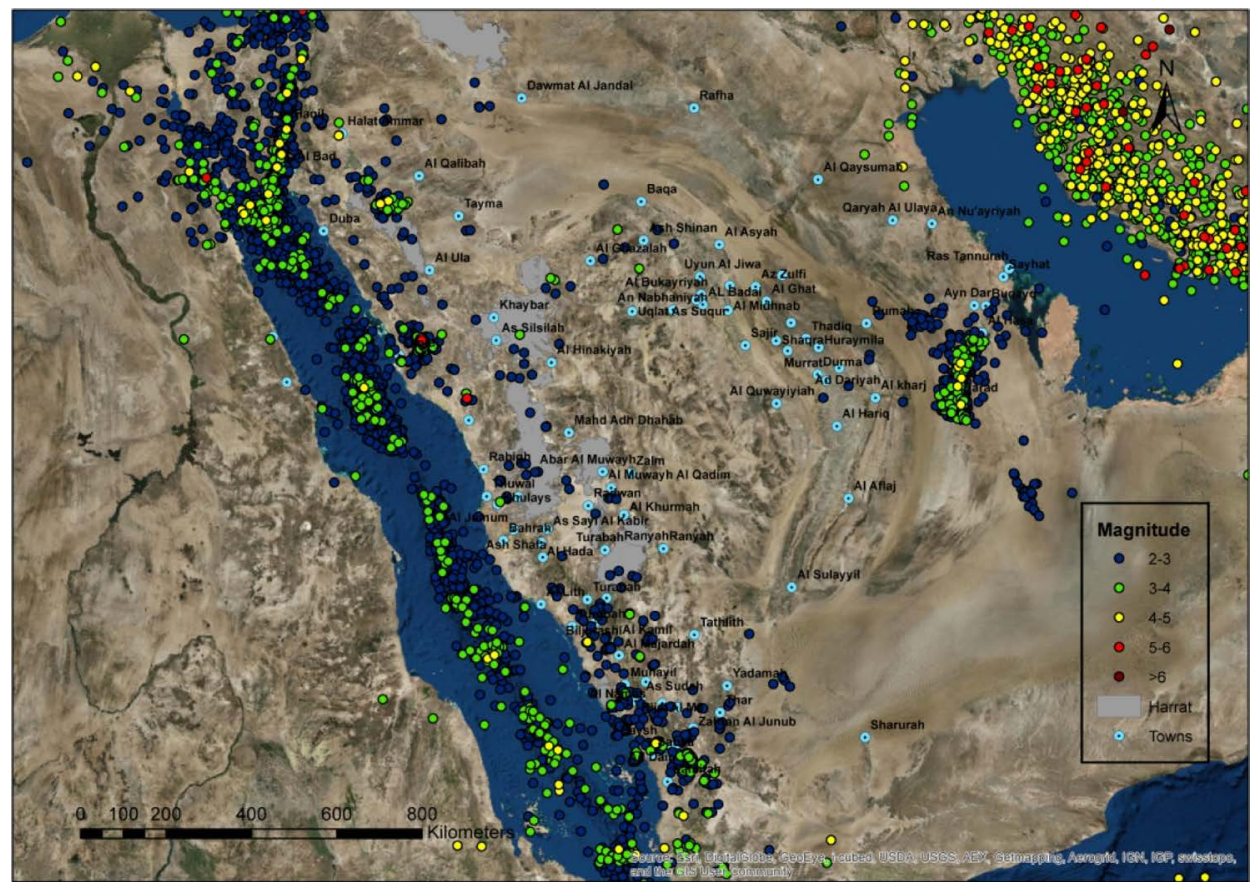

Figure 1. Red sea, west coast of Saudi Arabia, seismic foci in Saudi Arabia and solutions in all the years until 2015. 


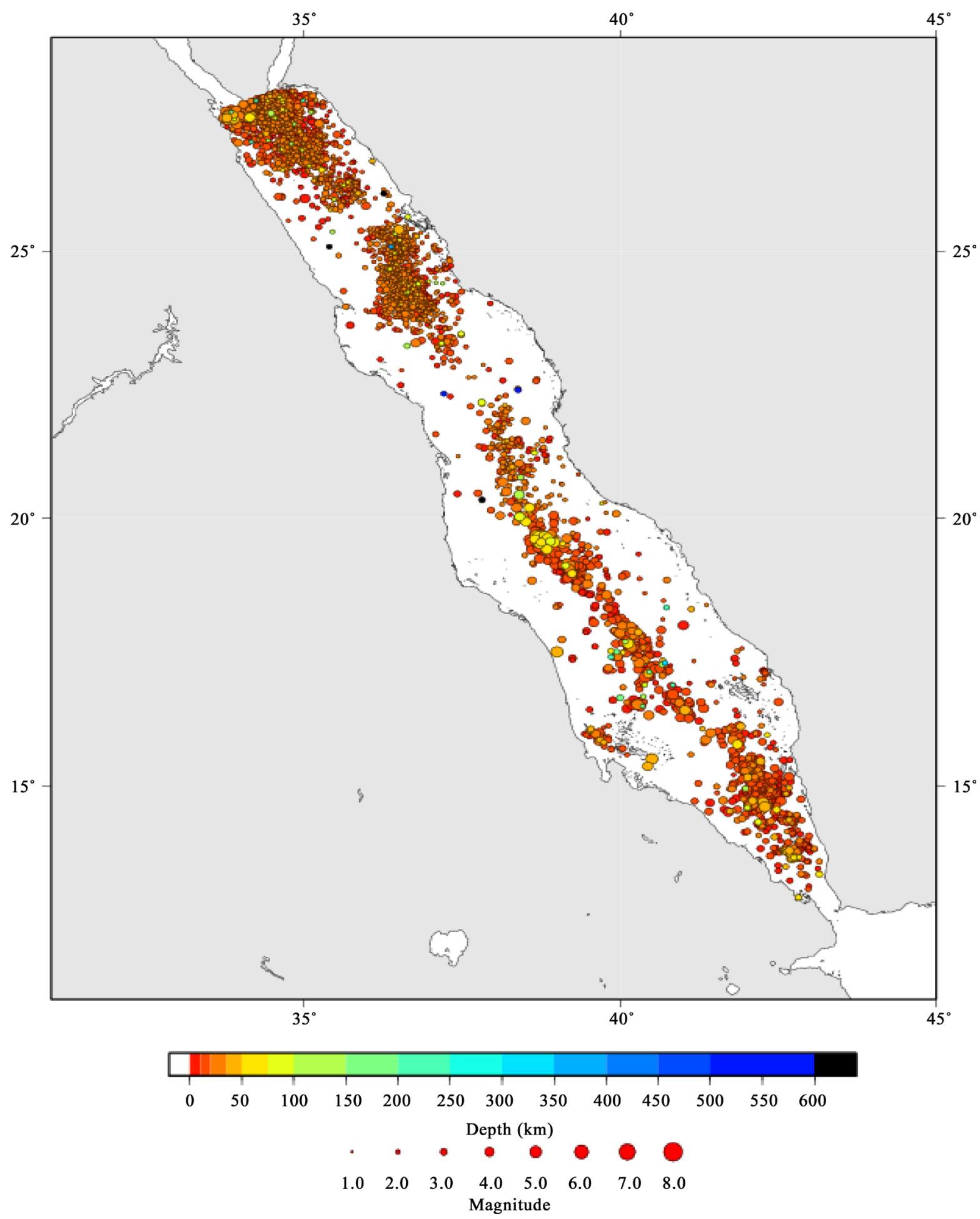

Figure 2. Earthquake intensity map for the western region, west coast, return period $=100$ years.

\subsection{Seismicity of Red Sea (Figure 2)}

Red Sea is a body of water located between the western coast of the Arabian Peninsula and Africa. The overlooking countries on the Red Sea are: Saudi Arabia, Egypt, Sudan, Yemen, Eritrea and Djibouti. Its strategic movement of marine transportation as connection of the South Ocean through the Strait of Bab el Mandeb and extending north 
to reach the Sinai Peninsula, and there are branches off to the Gulf of Aqaba and the Gulf of Suez, which leads to the Suez Canal. The length of this sea 1900 kilometers and currently up in some areas to $300 \mathrm{~km}$. The deepest point in the Red Sea up to $2500 \mathrm{~m}$ and the rate of decline is $500 \mathrm{~m}$. Red Sea, an area of 450,000 $\mathrm{km}^{2}$.

\section{Literature Review}

When looking around us to natural disasters, particularly earthquakes, we find they are warning of a disaster are taken into account in the event of predictable after a study and give warning of potentially harmful earthquakes in enough time to prepare appropriate for this disaster and minimize the loss of life and property [5]. Many studies have been presented to develop reliable estimates, of probability, magnitude and recurrence relations given the large pattern of earthquake occurrence. The primary advantage of probabilistic seismic hazard analysis (PSHA) is that it integrates over all seismicity: temporal and spatial along with ground motions to calculate a combined probability of exceedence, which incorporates the relative frequencies of occurrence of different earthquakes and ground-motion characteristics. Practically in any earthquake catalogue the quality of different parts (periods and areas) varies significantly with respect to completeness, magnitude reliability, homogeneity and location accuracy [6]-[8].

[9] El-Quliti in [10] estimated the frequency, magnitude and recurrence of extreme earthquakes in Medina Area in Saudi Arabia. Statistical theory of extreme values has been used to analyze the observed extremes of any phenomena and to forecast the further extremes based on the appropriate distribution, Gumbel [11]. In earthquake engineering, this theory has been applied successfully by many researchers in the past few decades (Nordquist [12]; Epstein [13]; Yegulalp [14]; Al-Abbasi [15] and Jaiswal [16]. This theory does not require analysis of the complete record of earthquake occurrence, but uses the sequence of earthquakes constructed from the largest values of the magnitude over a set of predetermined intervals.

Abe and Suzuki [17] analyzed the seismic data from the viewpoint of science of complexity, where one of the main goals of seismology is to predict when and where the next main shock will occur after an earlier main shock. The rate of recurrence of earthquakes on a seismic source can be represented with the Gutenberg-Richter relation [18]. Kasap and Gürlen [19] studied the return periods of earthquakes. Ogata [20] investigated the statistical models for earthquake occurrences. Utsu [21] applied gamma, log-normal, Weibull and exponential distributions to describe the probability distribution of inter-occurrence time of large earthquakes in Japan. Aktaş et $a l$. [20], used Poisson distribution to describe the recurrence times, and estimated the expected value and variance computed for the loss of life and damaged buildings after the change point using the compound Poisson process. Bayrak et al. [21] evaluated the seismicity and earthquake hazard parameters of Turkey based on maximum regional magnitude. Öztürk et al. [22] estimated the mean return periods, the most probable magnitude in a time period of t-years, and the probability of earthquake occurrence for a given magnitude during a time span of t-years for different regions in and around Turkey. They also showed that in the specific region, the most probable earthquake magnitude in the next 100 years would be over 7.5 [23]. The goodness of fit is evaluated employing Kolmogorov-Smirnov test [24].

\section{Extreme Earthquake Analysis}

Earthquake prediction can be considered into two types. First is the statistical prediction which is based on previous events; Data are collected from the records. Second is deterministic prediction which is made from the earthquake signs. Table 1 shows the data for earthquakes in Red Sea province and surrounding area representing the range and maximum magnitude.

Most extreme event analysis is concerned with the distribution of annual maximum or minimum values at a given site. These events are given a rank, $m$, starting with $m=1$ for the highest value, $m=2$ for the next highest and so on in descending order. Each earthquake magnitude is associated with a rank, $m$, with $m=1$ given to the maximum magnitude over the years of record, $m=2$ given to the second highest magnitude, $m=3$ given to the third highest one, etc. The smallest earthquake magnitude will receive a rank equal to the number of years over which there is a record, $n$. Thus, the discharge with the smallest value will have $m=n=100$.

There are several formulas for calculating the probability value. The Weibull formula will be used because of its ease of use. The US Geological Survey [25], among others, also uses this formula.

According to the Weibull equation [24] the return period or recurrence interval $T$ (in years) is calculated using the following equation: 
Table 1. Data for the earthquakes in red sea province.

\begin{tabular}{|c|c|c|c|c|}
\hline Year & Number of Earthquakes & Minimum Magnitude & Range & Maximum Magnitude \\
\hline 1913 & 1 & 5.8 & $5.8-5.8$ & 5.8 \\
\hline 1921 & 1 & 5.6 & $5.6-5.6$ & 5.6 \\
\hline$\ldots$ & & & & \\
\hline 1962 & 2 & 4.8 & $4.8-5.3$ & 5.3 \\
\hline 1964 & 1 & 4.8 & $48-48$ & 48 \\
\hline 1965 & 1 & 4.1 & $4.1-4.1$ & 4.1 \\
\hline 1967 & 28 & 4.1 & $4.1-5.6$ & 5.6 \\
\hline 1969 & 19 & 4.5 & $4.5-6.1$ & 6.1 \\
\hline 1970 & 3 & 4.5 & $4.5-4.8$ & 4.8 \\
\hline 1971 & 1 & 4.8 & $4.8-4.8$ & 4.8 \\
\hline 1972 & 1 & 5.1 & $5.1-5.1$ & 5.1 \\
\hline . & & & & \\
\hline 1974 & 3 & 4.4 & $4.4-5.1$ & 5.1 \\
\hline 1975 & 6 & 4.6 & $4.6-5.3$ & 5.3 \\
\hline 1976 & 6 & 4.3 & $4.3-4.8$ & 4.8 \\
\hline 1977 & 1 & 5.9 & $5.9-5.9$ & 5.9 \\
\hline 1978 & 4 & 4.4 & $4.4-5.1$ & 5.1 \\
\hline 1979 & 7 & 4.1 & $4.1-5.1$ & 5.1 \\
\hline 1980 & 11 & 4.3 & $4.3-5.4$ & 5.4 \\
\hline 1982 & 2 & 4.6 & $4.6-4.8$ & 4.8 \\
\hline 1983 & 2 & 4.1 & $4.1-4.7$ & 4.7 \\
\hline 1984 & 9 & 3.1 & $3.1-4.7$ & 4.7 \\
\hline 1985 & 4 & 3.7 & $3.7-4.6$ & 4.6 \\
\hline 1986 & 3 & 3.4 & $3.4-4.7$ & 4.7 \\
\hline 1987 & 2 & 4.7 & $4.7-4.9$ & 4.9 \\
\hline 1988 & 16 & 3.8 & $3.8-5.3$ & 5.3 \\
\hline 1989 & 4 & 2.1 & $2.1-4.2$ & 4.2 \\
\hline 1990 & 4 & 4.2 & $4.2-4.8$ & 4.8 \\
\hline 1991 & 5 & 2.9 & $2.9-4.7$ & 4.7 \\
\hline 1992 & 11 & 2.4 & $2.4-4.5$ & 4.5 \\
\hline 1993 & 65 & 2.3 & $2.3-5.6$ & 5.6 \\
\hline 1994 & 21 & 2.3 & $2.3-4.9$ & 4.9 \\
\hline 1995 & 15 & 2.4 & $2.4-4.3$ & 4.3 \\
\hline 1996 & 41 & 2 & $2-5$ & 5 \\
\hline 1997 & 40 & 2.3 & $2.3-5.5$ & 5.5 \\
\hline 1998 & 25 & 2 & $2-4.2$ & 4.2 \\
\hline 1999 & 7 & 3.3 & $3.3-4.4$ & 4.4 \\
\hline 2000 & 77 & 1.5 & $1.5-4.9$ & 4.9 \\
\hline 2001 & 206 & 1.5 & $1.5-4.8$ & 4.8 \\
\hline 2002 & 477 & 1.3 & $1.3-4.5$ & 4.5 \\
\hline
\end{tabular}




\begin{tabular}{|c|c|c|c|c|}
\hline \multicolumn{5}{|c|}{ Continued } \\
\hline 2003 & 255 & 1 & $1-4.6$ & 4.6 \\
\hline 2004 & 553 & 0.8 & $0.8-4.6$ & 4.6 \\
\hline 2005 & 386 & 0.7 & $0.7-4.3$ & 4.3 \\
\hline 2006 & 124 & 0.4 & $0.4-4.7$ & 4.7 \\
\hline 2007 & 616 & 0 & $0-4.5$ & 4.5 \\
\hline 2008 & 1037 & 0 & $0-4.2$ & 4.2 \\
\hline 2009 & 52 & 2.1 & $2.1-4.7$ & 4.7 \\
\hline 2010 & 66 & 0.1 & $0.1-4.4$ & 4.4 \\
\hline 2011 & 681 & 0.2 & $0.2-4.5$ & 4.5 \\
\hline 2012 & 117 & 1.3 & $1.3-4.5$ & 4.5 \\
\hline 2013 & 79 & 2.3 & $2.3-5.4$ & 5.4 \\
\hline 2014 & 25 & 3.1 & $3.1-4.1$ & 4.1 \\
\hline 2015 & 13 & 3.5 & $3.5-4.1$ & 4.1 \\
\hline
\end{tabular}

$$
T(\text { years })=(n+1) / m
$$

where: $m=$ event ranking (in a descending order), and $n=$ number of events in the period of record.

The percentage probability the (annual exceedence probability) for each magnitude is calculated using the inverse of the Weibull equation as follows:

$$
P(\text { percent })=100 \cdot m /(n+1) \text {. }
$$

From Equations ((1) and (2)) it is clear that $P=100 / T \%$. For example, an earthquake equal to that of a 10 year one would have an annual exceedence probability of $1 / 10=0.1 \%$ or $10 \%$. This would say that in any given year, the probability that an earthquake with a magnitude equal to or greater than that of a 10 year earthquake would be $0.1 \%$ or $10 \%$. Similarly, the probability of an earthquake with a magnitude exceeding the 50 year one in any given year would be $1 / 50=0.02$, or $2 \%$. Note that such probabilities are the same for every year, but in practice, such an earthquake could occur next year, or be exceeded several times in the next 50 years.

Table 1 shows the Number of Earthquakes, Minimum Magnitude, Range, and Maximum Magnitude for the years 1913 to 2016 [26].

Table 2 shows the calculations of the rank $m$, the probability $P$ and the return period $T$ for the data of the yearly maximum magnitude given in Table 1 . The return period or recurrence interval $T$ (in years) and the probability (P) are calculated using Equations ((1), (2)).

\section{Earthquake Parameters}

\subsection{Annual Exceedence Probability and Return Period}

Return period or Recurrence interval is the average interval of time within which a flood of specified magnitude is expected to be equaled or exceeded at least once. 100 year earthquake is an earthquake that is expected to occur, on the average, once every 100 years, or has a one percent chance of occurring each year.

Figure 3 is a plot of earthquake magnitude and annual exceedence probability relationship (linear scales) with the annual maximum magnitude per year on the $\mathrm{Y}$ axis versus the annual exceedence probability on the $\mathrm{X}$ axis. The $\mathrm{X}$ and $\mathrm{Y}$ axes both use linear scales.

A best-fit curve is drawn through the data points. From the best-fit curve, one can determine the earthquake magnitude associated with an earthquake with a recurrence interval of say 10 years, it is about 5.8 on Richter scale. This would be called the 10 -year earthquake.

Similarly the recurrence interval associated with an earthquake magnitude of magnitude of 5 on Richter scale is about 17 year.

The annual peak information may also be presented with a logarithmic rather than a linear scale. This is often done to make the curve appear as a straight line and also to avoid a graph that will suggest either a zero or a one- 
Table 2. The rank, probability and the return period results.

\begin{tabular}{|c|c|c|c|c|}
\hline Rank (m) & Year & Maximum Magnitude & Probability (P) \% & Period of return $(\mathrm{T})$ \\
\hline 1 & 1969 & 6.1 & 0.961538462 & 104 \\
\hline 2 & 1977 & 5.9 & 1.923076923 & 52 \\
\hline 3 & 1913 & 5.8 & 2.884615385 & 34.66666667 \\
\hline 4 & 1993 & 5.6 & 3.846153846 & 26 \\
\hline 5 & 1967 & 5.6 & 4.807692308 & 20.8 \\
\hline 6 & 1921 & 5.6 & 5.769230769 & 17.33333333 \\
\hline 7 & 1997 & 5.5 & 6.730769231 & 14.85714286 \\
\hline 8 & 2013 & 5.4 & 7.692307692 & 13 \\
\hline 9 & 1980 & 5.4 & 8.653846154 & 11.55555556 \\
\hline 10 & 1988 & 5.3 & 9.615384615 & 10.4 \\
\hline 11 & 1975 & 5.3 & 10.57692308 & 9.454545455 \\
\hline 12 & 1962 & 5.3 & 11.53846154 & 8.6666666667 \\
\hline 13 & 1979 & 5.1 & 12.5 & 8 \\
\hline 14 & 1978 & 5.1 & 13.46153846 & 7.428571429 \\
\hline 15 & 1974 & 5.1 & 14.42307692 & 6.933333333 \\
\hline 16 & 1972 & 5.1 & 15.38461538 & 6.5 \\
\hline 17 & 1996 & 5 & 16.34615385 & 6.117647059 \\
\hline 18 & 2000 & 4.9 & 17.30769231 & 5.777777778 \\
\hline 19 & 1994 & 4.9 & 18.26923077 & 5.473684211 \\
\hline 20 & 1987 & 4.9 & 19.23076923 & 5.2 \\
\hline 21 & 2001 & 4.8 & 20.19230769 & 4.952380952 \\
\hline 22 & 1990 & 4.8 & 21.15384615 & 4.727272727 \\
\hline 23 & 1982 & 4.8 & 22.11538462 & 4.52173913 \\
\hline 24 & 1976 & 4.8 & 23.07692308 & 4.333333333 \\
\hline 25 & 1971 & 4.8 & 24.03846154 & 4.16 \\
\hline 26 & 1970 & 4.8 & 25 & 4 \\
\hline 27 & 1964 & 4.8 & 25.96153846 & 3.851851852 \\
\hline 28 & 2009 & 4.7 & 26.92307692 & 3.714285714 \\
\hline 29 & 2006 & 4.7 & 27.88461538 & 3.586206897 \\
\hline 30 & 1991 & 4.7 & 28.84615385 & 3.4666666667 \\
\hline 31 & 1986 & 4.7 & 29.80769231 & 3.35483871 \\
\hline 32 & 1984 & 4.7 & 30.76923077 & 3.25 \\
\hline 33 & 1983 & 4.7 & 31.73076923 & 3.151515152 \\
\hline 34 & 2004 & 4.6 & 32.69230769 & 3.058823529 \\
\hline 35 & 2003 & 4.6 & 33.65384615 & 2.971428571 \\
\hline 36 & 1985 & 4.6 & 34.61538462 & 2.888888889 \\
\hline 37 & 2012 & 4.5 & 35.57692308 & 2.810810811 \\
\hline 38 & 2011 & 4.5 & 36.53846154 & 2.736842105 \\
\hline 39 & 2007 & 4.5 & 37.5 & 2.6666666667 \\
\hline 40 & 2002 & 4.5 & 38.46153846 & 2.6 \\
\hline 41 & 1992 & 4.4 & 39.42307692 & 2.536585366 \\
\hline 42 & 2010 & 4.4 & 40.38461538 & 2.476190476 \\
\hline 43 & 1999 & 4.4 & 41.34615385 & 2.418604651 \\
\hline
\end{tabular}




\section{Continued}

\begin{tabular}{lllcc}
\hline 44 & 2005 & 4.3 & 42.30769231 & 2.363636364 \\
45 & 1995 & 4.3 & 43.26923077 & 2.311111111 \\
46 & 2008 & 4.2 & 44.23076923 & 2.260869565 \\
47 & 1998 & 4.2 & 45.19230769 & 2.212765957 \\
48 & 1989 & 4.2 & 46.15384615 & 2.166666667 \\
49 & 2015 & 4.1 & 47.11538462 & 2.12244898 \\
50 & 2014 & 4.1 & 48.07692308 & 2.039215686 \\
51 & 1965 & 4.1 & 49.03846154 & \\
\hline$\ldots \ldots \ldots$ & & & & \\
\hline
\end{tabular}

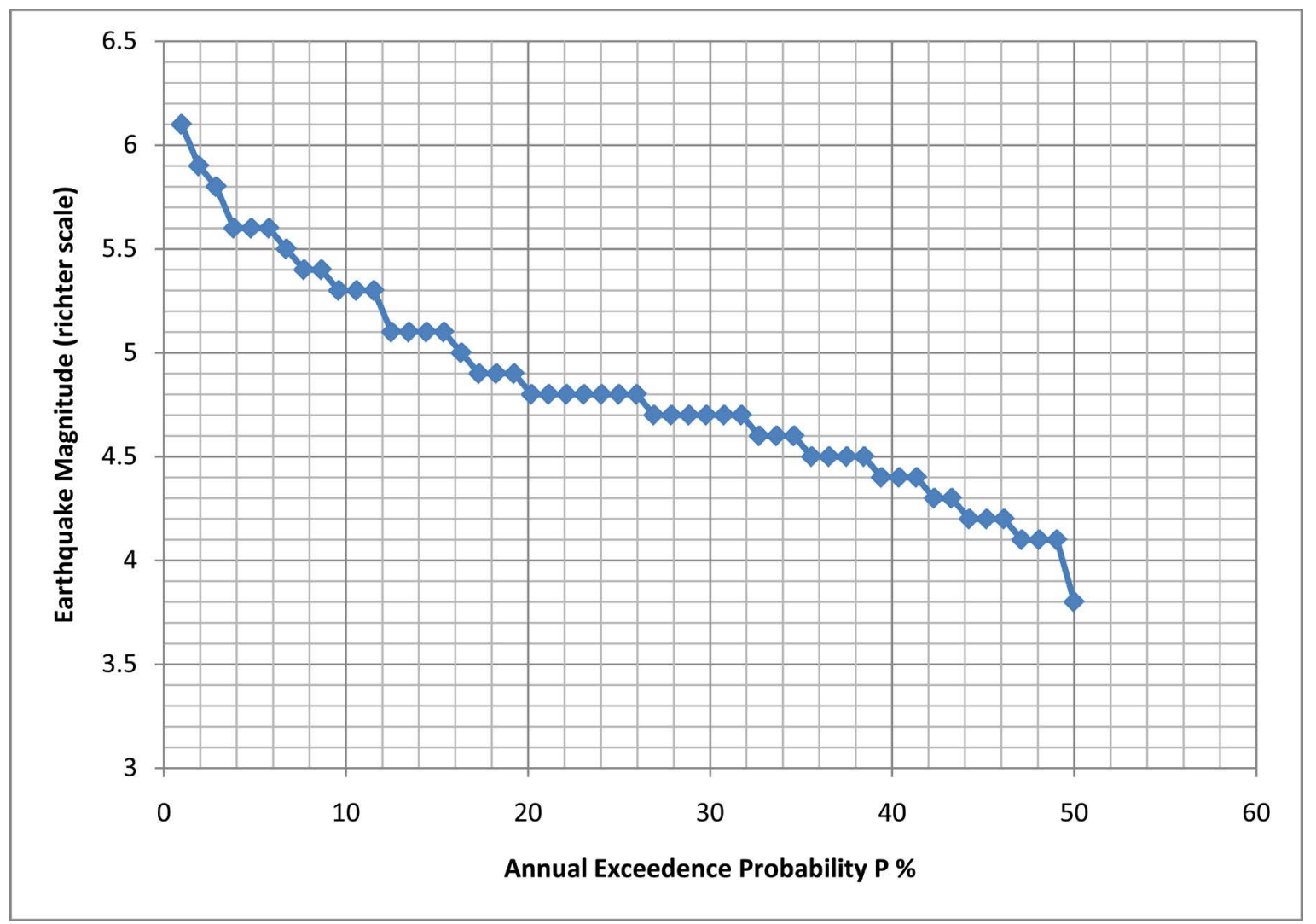

Figure 3. Earthquake magnitude and probability relationship (linear scales).

hundred percent exceedance probability. Moreover, a straight line curves are more easily allow extrapolation beyond the data extremes.

Figure 4 represents the earthquake magnitude and the annual exceedance probability (log scale) relationship.

Percentage probability is determined by dividing one by the recurrence interval and multiplying by 100 . For example, the probability that an earthquake magnitude will exceed the 100-year earthquake this year or any other year would be $1 \%$.

Figure 5 shows the earthquake magnitude and return period relationship on linear scales and Figure 6 shows the earthquake magnitude and return period relationship using a log scale. From the figure it can be noticed that the return period of an earthquake of magnitude 6.1 on Richter scale is about 104 years, and an earthquake of magnitude of 5.8 on Richter scale has a recurrence interval of about 34.6 years. 
Sometimes it is suitable to add a second $\mathrm{X}$-axis to represent the return period to the first $\mathrm{X}$-axis representing the annual exceedance probability.

Figure 7 shows the earthquake magnitude and the annual exceedance probability on the first $\mathrm{X}$-axis and the return period on the second $\mathrm{X}$-axis. Both the two $\mathrm{X}$-axes use a variable scale so the relationship appears as a perfect straight line, this will allow for easier findings.

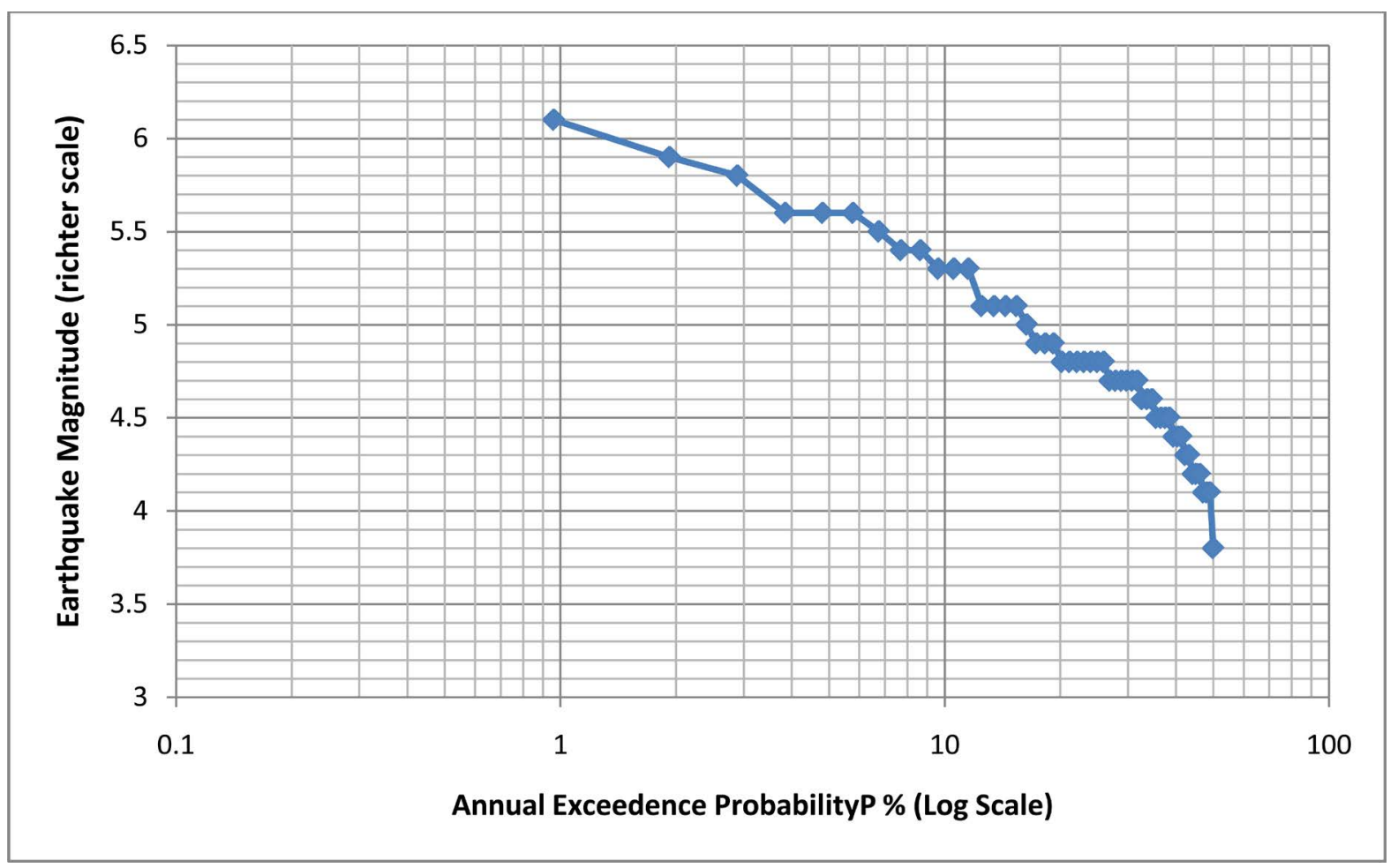

Figure 4. Earthquake magnitude and annual exceedence probability relationship (log scale).

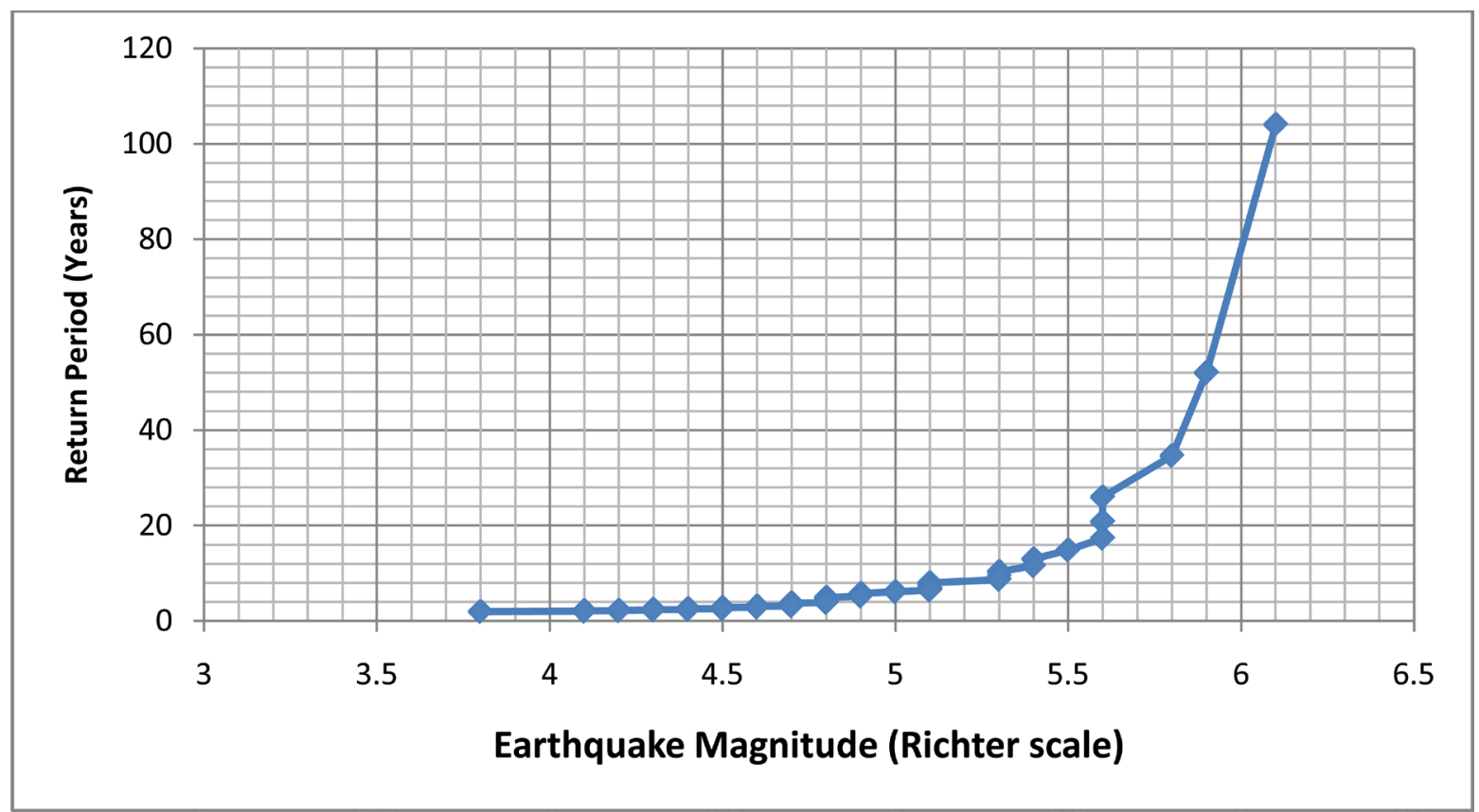

Figure 5. Earthquake magnitude and return period relationship (linear scales). 


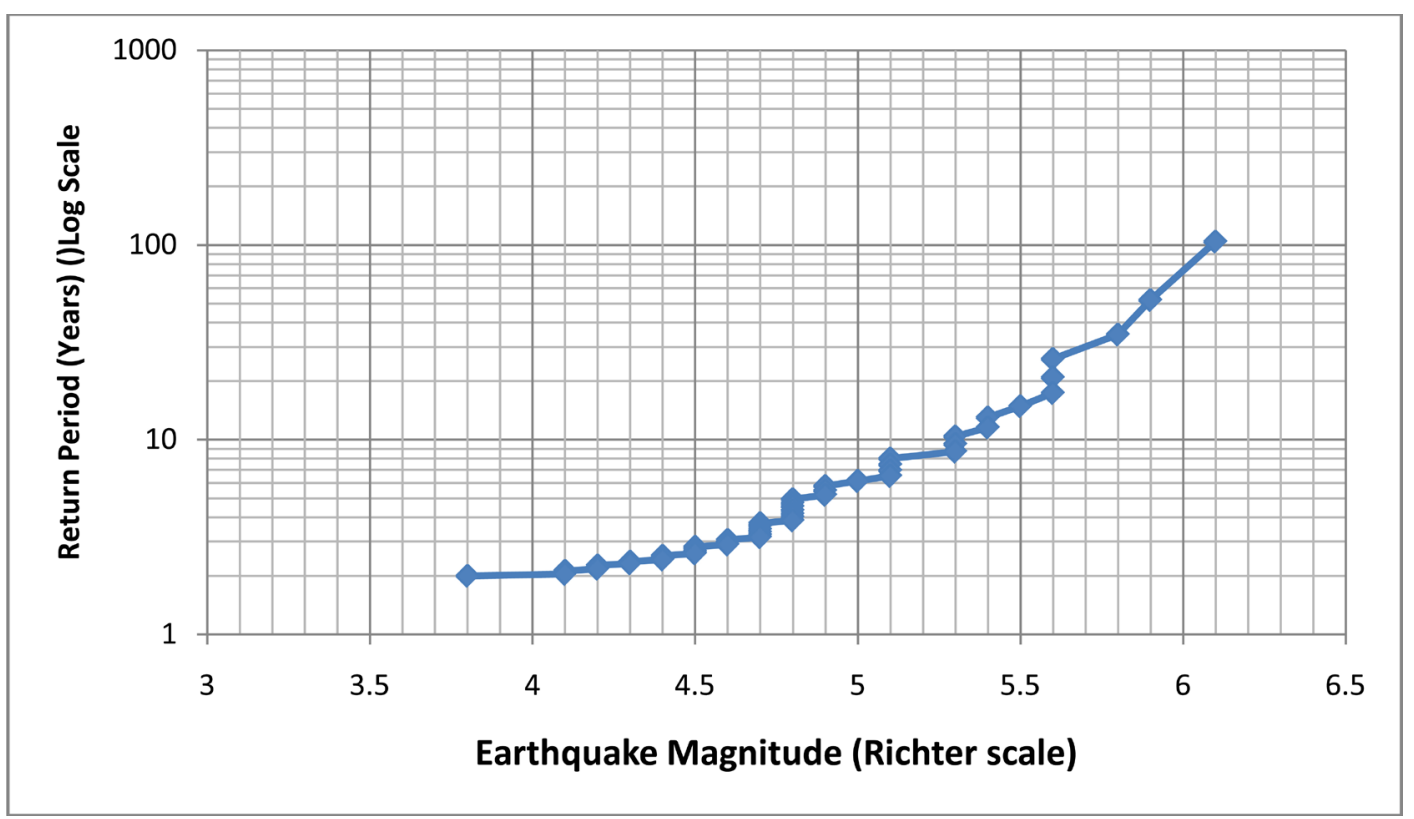

Figure 6. Earthquake magnitude and return period relationship (loq scale).

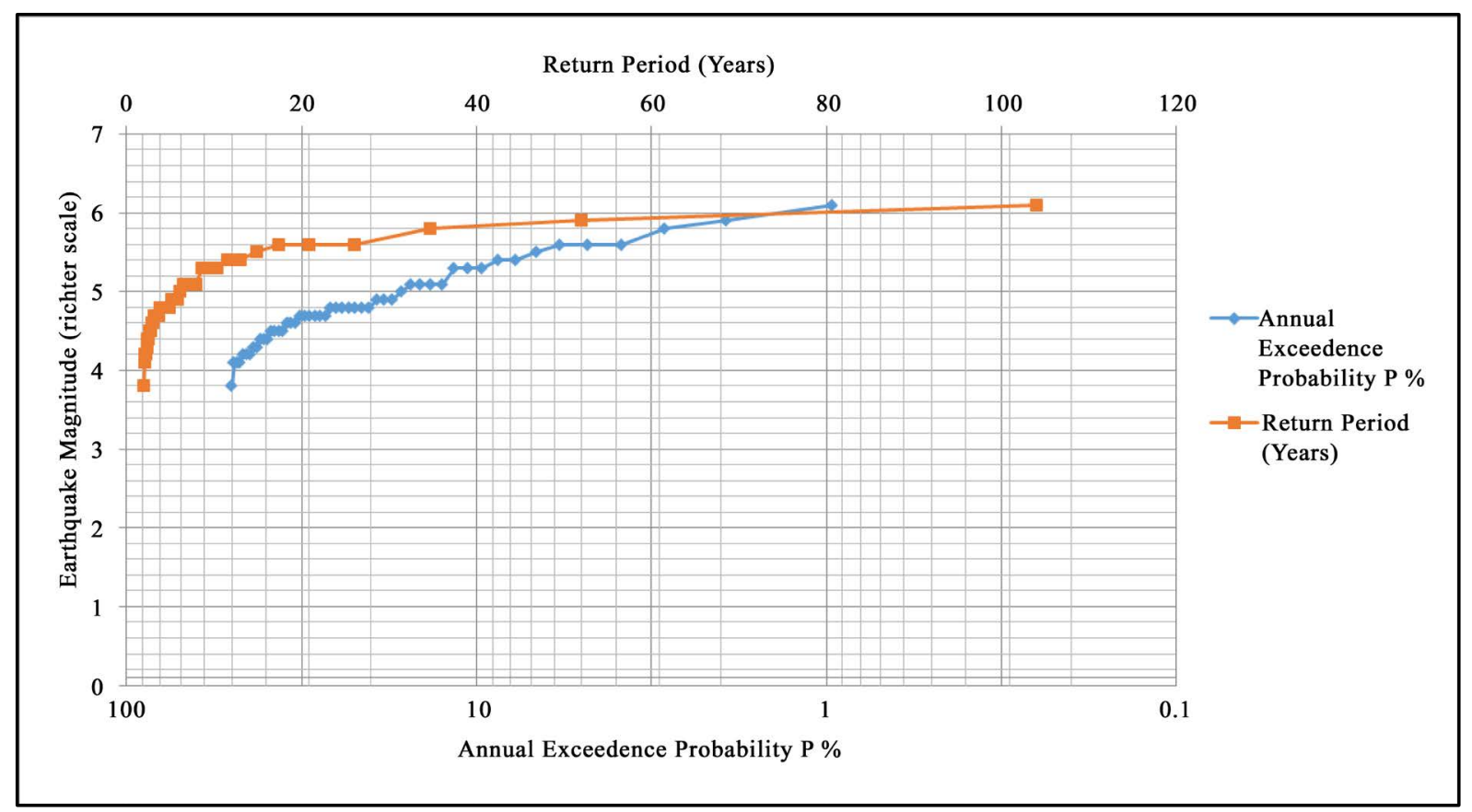

Figure 7. Earthquake magnitude probability and return period relationship.

From the fit line, one can determine the magnitude associated with an earthquake of a recurrence interval of say 30 years. This would be called the 30-year earthquake. The magnitude associated with the 30-year earthquake is about 5.8 Richter scale. Similarly the magnitude associated with an earthquake with a recurrence interval of 104 years (the 104-year earthquake) would have a measure of about 6.1 Richter scale.

\subsection{The Probability during a Time Period}

The probability of a certain-magnitude earthquake occurring during any period $\boldsymbol{t}$ can be calculated using the following equation: 


$$
P t=1-(1-P) t
$$

where $P$ is the probability of occurrence over the entire time period, $t$, and $P$ is the probability of occurrence in any year.

It is worth to apply Equation (3) for earthquakes of highest magnitudes which represent the most dangerous events in the location. The equation is applied for earthquakes of magnitudes 6.1, 5.9 and 5.8 Richter scale of probabilities of $0.96 \%, 1.92 \%$ and $2.88 \%$ respectively. The result is depicted in Figure 8 for earthquakes of magnitudes: 6.17 Richter scale ( $P=0.96 \%)$, 5.9 Richter scale $(P=1.92 \%)$ and 5.8 Richter scale $(P=2.88 \%)$.

A homeowner considering the costs of reinforcing a house against earthquakes will want to know how the risk varies during an average mortgage span of 30 years.

Figure 9 shows the earthquake probability and earthquake magnitudes in a time span of 30 years. An earthquake of magnitude of 4.5 on Richter scale for example, has a $100 \%$ probability of occurrence but, if the earthquake of magnitude 6.1 on Richter scale is chosen, the probability drops to $25 \%$.

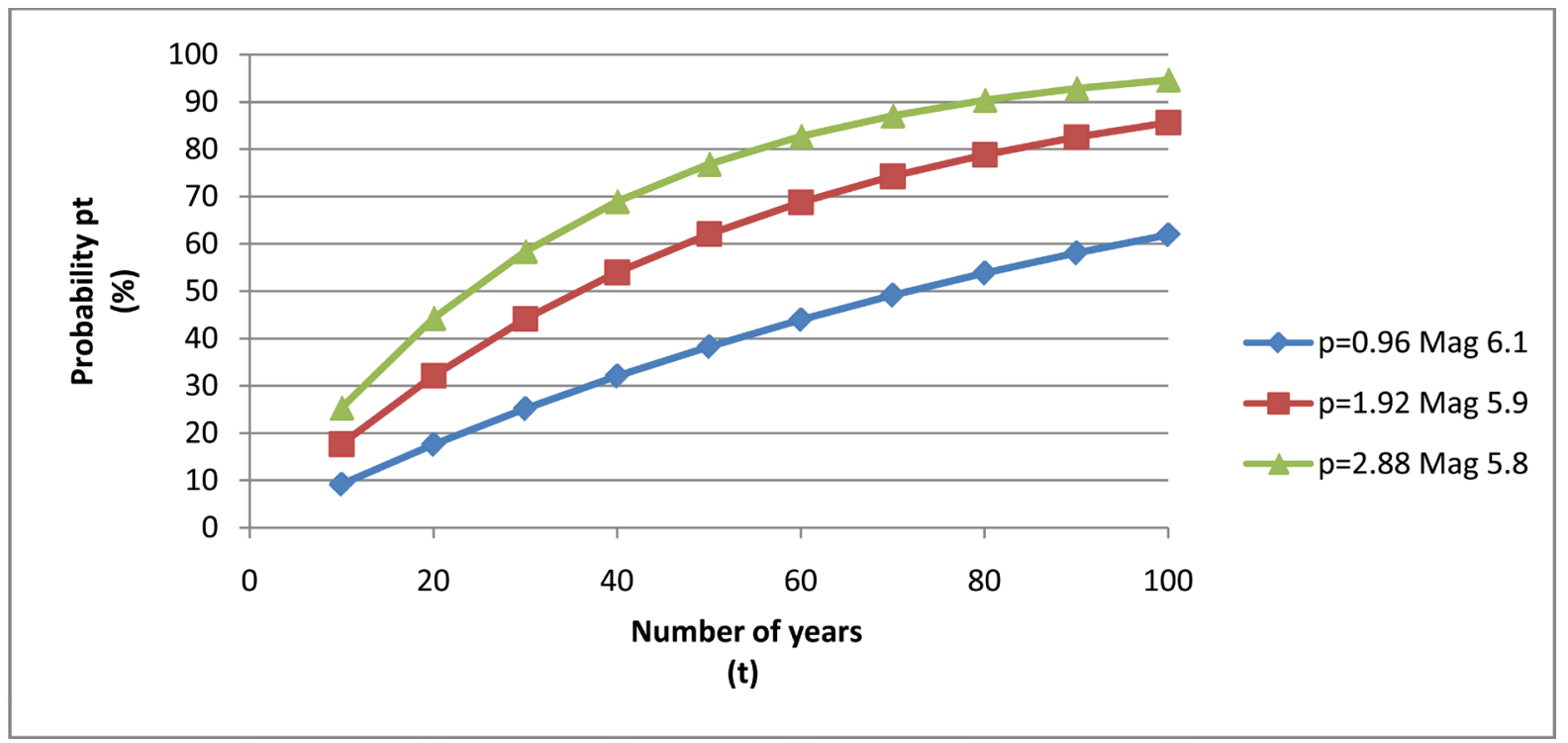

Figure 8. Earthquake probability for some earthquake magnitudes in a time span period.

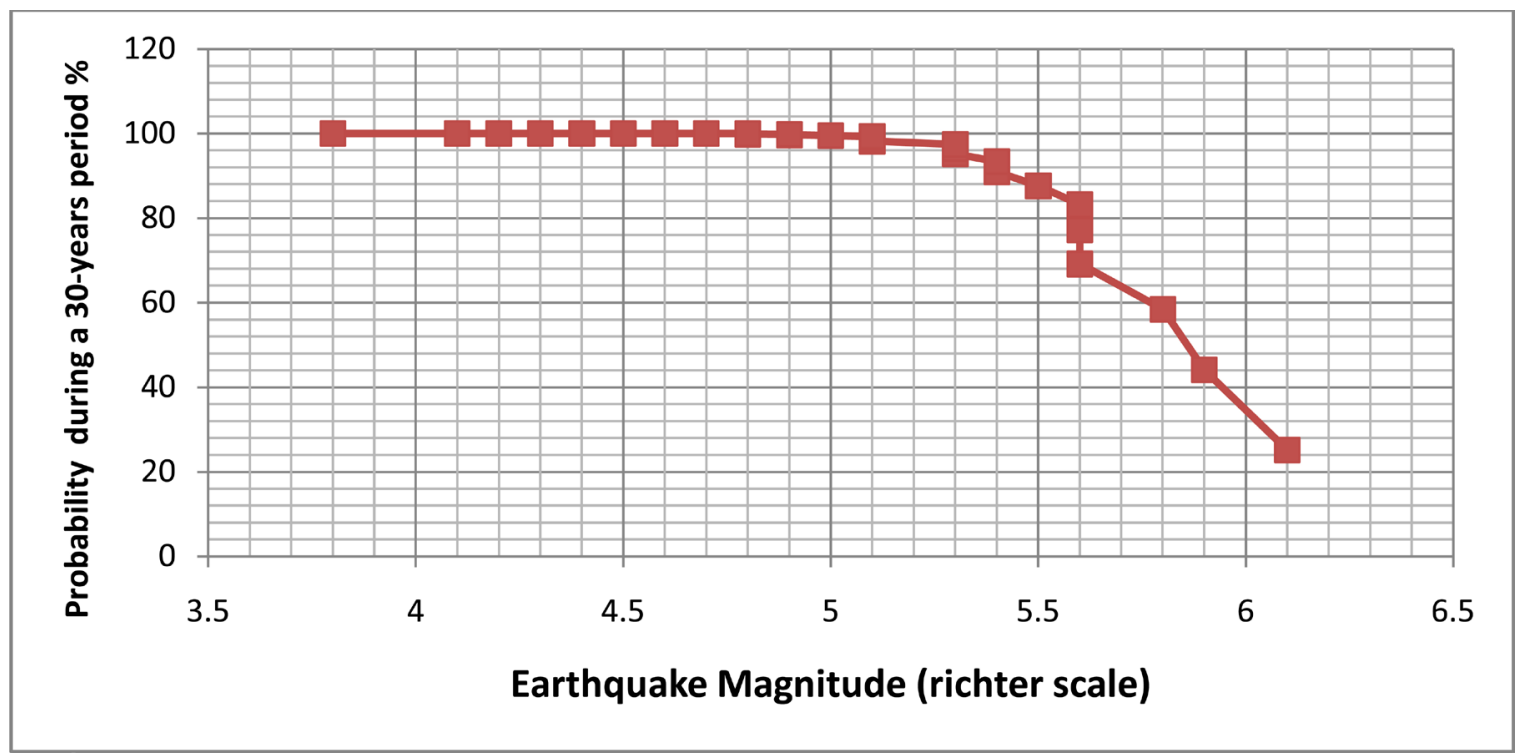

Figure 9. Earthquake probability and earthquake magnitudes in a time span of 30 years. 


\section{Conclusions and Points for Future Researches}

\subsection{Conclusions}

In this study, the statistical frequency analyses are applied to the recorded annual maximum earthquake magnitudes for Rea Sea province and the surrounding area in the westcoast of Saudi Arabia since 1913.

The risk of earthquakes, the return period and the probability of occurrence for a particular magnitude during any given year are calculated based on the analysis of data over a period of 104 years by applying Weibull equations.

The relation between magnitude and frequency and between magnitude and return period is represented as a curve in a linear scale graph and as a straight line on a logarithmic scale and variable scale graphs to facilitate the findings. The results lead to a general conclusion that Red Sea is considered to be located within the existing areas of the seismic belt and the region is exposed to earthquakes with strength ranging about 3.0 or less on the Richter scale with a high probability. The maximum magnitude is 6.1 with a return period of 100 years and probability of about $0.96 \%$.

The conventional approach of hazard estimation based on magnitude frequency relationship is more useful when the dataset is complete for the entire time span and for the magnitude range. With good and complete datasets, the method is more appropriate and accurate for seismic hazard estimation.

\subsection{Points for Future Researches}

Points for future researches can be summarized as follows:

- To study in details the influence of missed data like that for the years in the intervals (1913-1921), (1921-1962), (1962-1964), (1965-1967), (1967-1969) and 1980-1982) on the earthquake parameters.

- There are several methods of comparing the results of evaluation of earthquake parameters and can be applied in other areas in the Kingdom of Saudi Arabia

- Can assess the risk parameters for a number of potential risks in Saudi Arabia, an example of the risks of landslides; severe storms; floods.

- Drawing seismic maps of the areas in which they are registered seismic activity in Saudi Arabia each year for use in the evaluation and the likelihood of the occurrence of such activity on a long-term process.

\section{References}

[1] Ashour, S.A. and Abdel-Rahman, H.H. (1994) Application of Seismic Risk Analysis and Earthquake Simulation Methods to the Western Region in Saudi Arabia. Journal of King Abdulaziz University-Engineering Sciences, 6, 3-23.

[2] Barazangi, M. (1981) Evaluation of Seismic Risk along the Western Part of the Arabian Plate: Discussion and Recommendations. Bulletin of Faculty of Earth Science, 4, 77-87.

[3] Merghelani, H.M. (1979) Seismicity of the Tihamat-Asir Region, Kingdom of Saudi Arabia. US Geological Survey Saudi Arabian Project Report 251, 20.

[4] Brillinger, D.R. (1993) Earthquake Risk and Insurance. Environmetrics, 4, 1-21. http://dx.doi.org/10.1002/env.3170040102

[5] Ameer, S.A., Sharma, M.L. and Wason, H.R. (2002) Maximum Likelihood Estimation of Seismic Hazard for Iraq from Complete Data Files. Proceedings of the 12th Symposium on Earthquake Engineering, Roorkee, India, Vol. 1, 306312.

[6] Ameer, S.A., Sharma, M.L. and Wason, H.R. (2002) Completeness of Earthquake Catalogue and Its Implications in Seismic Hazard Estimation-A Case Study for Iraq. Proceedings of the 12th Symposium on Earthquake Engineering, Roorkee, India, Vol. 1, 342-349. http://dx.doi.org/10.1007/s00024-004-2650-y

[7] Ameer, S.A., Sharma, M.L., Wason, H.R. and Alsinawi, S.A. (2005) Probabilistic Seismic Hazard Assessment for Iraq Using Complete Earthquakes Catalogue Files. Pure \& Applied Geophysics, 162, 951.

[8] ElQuliti, S.A. (2016) Estimating the Frequency, Magnitude and Recurrence of Extreme Earthquakes in Medina Area in Saudi Arabia. (Poster) First Saudi Conference on the Environment, Prince Sultan Center for Environmental and Tourist Studies and Research, King Khalid University, Abha, Saudi Arabia, March 2016.

[9] Gumbel, E. (1958) Statistics of Extremes, Columbia University Press, New York, USA.

[10] Nordquist, J.M. (1945) Theory of Largest Values Applied to Earthquake Magnitudes. Transactions American Geophysical Union, 26, 29-31. 
[11] Epstein, B. and Lomnitz, C. (1966) A Model for the Occurrence of Large Earthquakes. Nature, 211, 954-956. http://dx.doi.org/10.1038/211954b0

[12] Yegulalp, T.M. and Kuo, J.T. (1974) Statistical Prediction of the Occurrence of Maximum Magnitude Earthquakes. Bulletin of the Seismological Society of America, 64, 393. http://dx.doi.org/10.1016/0148-9062(74)91161-9

[13] Fahmi, K.J. and Al Abbasi, J.N. (1991) GEMPAK: A Fortran 77 Program for Calculating Gumbel's First, Third and Mixture Upper Earthquake Magnitude Distributions Employing Maximum Likelihood Estimation. Computer and Geosciences, 17, 271-290. http://dx.doi.org/10.1016/0098-3004(91)90016-7

[14] Jaiswal, K., Gupta, S. and Sinha, R. (2002) Estimation of Maximum Magnitude Earthquakes in Peninsular India Using Extreme Value Statistics. 12th Symposium on Earthquake Engineering, IIT Roorkee, India.

[15] Abe, S. and Suzuki, N. (2005) Scale-Free Statistics of Time Interval between Successive Earthquakes. Physica A: Statistical Mechanics and Its Applications, 350, 588-596. http://dx.doi.org/10.1016/j.physa.2004.10.040

[16] Gutenberg, R. and Richter, C.F. (1944) Frequencies of Earthquakes in California. Bulletin of the Seismological Society of America, 34, 185-188.

[17] Kasap, R. and Gürlen, Ü. (2003) Deprem Magnitüdleri Için Tekrarlanma Yıllarının Elde Edilmesi: Marmara Bölgesi Örneği. Doğuş Üniversitesi Dergisi, 4, 157-166.

[18] Ogata, Y. (1988) Statistical Models for Earthquake Occurrences and Residual Analysis for Point Processes. Journal of the American Statistical Association, 83, 9-27. http://dx.doi.org/10.1080/01621459.1988.10478560

[19] Utsu, T. (1984) Estimation of Parameters for Recurrence Models of Earthquakes. Bulletin of the Earthquake Research Institute, 59, 53-66.

[20] Aktaş, S., Konşuk, H. and Yiğiter, A. (2009) Estimation of Change Point and Compound Poisson Process Parameters for the Earthquake Data in Turkey. Environmetrics, 20, 416-427. http://dx.doi.org/10.1002/env.937

[21] Bayrak, Y., Öztürk, S., Cinar, H., Kalafat, D., Tsapano, T.M., Koravos, G.Ch. and Leventakis, G.A. (2009) Estimating Earthquake Hazard Parameters from İnstrumental Data for Different Regions in and around Turkey. Engineering Geology, 105, 200-210. http://dx.doi.org/10.1016/j.enggeo.2009.02.004

[22] Öztürk, S., Bayrak, Y., Koravos, G.Ch. and Tsapanos, T.M. (2008) A Quantitative Appraisal of Earthquake Hazard Parameters Computed from Gumbel I Method for Different Regions in and around Turkey. Natural Hazards, 47, 471-495. http://dx.doi.org/10.1007/s11069-008-9234-6

[23] Bayrak, Y., Öztürk, S., Koravo, G.Ch., Leventakis, G.A. and Tsapanos, T.M. (2008) Seismicity Assessment for the Different Regions in and around Turkey Based on İnstrumental Data: Gumbel First Asymptotic Distribution and Gutenberg-Richter Cumulative Frequency Law. NHESS, 8, 1090-1122.

[24] Ameer, A.S., Sharma, M.L., Wason, H.R. and Alsinawi, S.A. (2004) Seismic Hazard Characterization and Risk Evaluation Using Gumbel's Method Of Extremes (G! and G3) and G_R Formula for Iraq. 13th World Conference on Earthquake Engineering, Vancouver, 1-6 August 2004, Paper No. 2898.

[25] The US Geological Survey Website. http://www.usgs.gov

[26] Şenocak, S., DÜzgÜn, O. and ŞengÜl, S. (2014) Frequency Analysis of Annual Maximum Earthquakes for Aşkale, Erzurum (Turkey) Province. Proceedings of the 5th European Conference of Civil Engineering (ECCIE'14), Florence, Italy, 22-24 November 2014. http://www.wseas.us/e-library/conferences/2014/Florence/SEMOTEC/SEMOTEC-08.pdf 